\title{
PRAEFATIO
}

Hac editione Concordantiarum, quam fundamentis usus editionis magnae 1 a me editae extruxi, continentur omnes loci Veteris Testamenti, quibus vocabulum, de quo agitur, occurrit, ita tamen, ut ipse qui vocatur contextus locorum non sit adscriptus. Loci numeris arabicis indicantur.

Eos locos, in quibus non modo vocabulum, sed tota sententia iteratur, cursivis numeris notavi. Quando vocabulum in uno eodemque versu repetitur, adiecto indice parvulo significavi, quotiens id factum sit (e. g. Mal 1, 62).

Utique hoc opus vice fungitur lexici analytici, in quo quaevis forma vocabulorum invenitur.

Cum particulas a me primum receptas verbis nominibusque alphabetico ordine adiunxerim, pronomina atque notam relationis separatim ex grammaticorum usu composui; itemque Buxtorfiom secutus Aramaicam partem a parte Hebraica separavi, ita ut de similitudine, quae intercedit inter linguas illas, in utraque parte lectorem moneam. Nomina propria non radicum plerumque incertarum, sed simpliciter alphabetico ordine disponenda putavi.

Omnibus radicibus latine translatis commentarii Hebraici additi sunt.

Quapropter spero ac confido, hoc opus summa diligentia perpolitum omnibus, qui sese studiis Hebraicis dederunt, adminiculum fore non contemnendum.

Lipsiae

\section{SOLOMON MANDELKERN}

1 Veteris Testamenti concordantiae hebraicae atque chaldaicae, quibus continentur cuncta quae in prioribus concordantiis reperiuntur vocabula, lacunis omnibus expletis emendatis cuiusquemodi vitiis, locis ubique denuo excerptis atque in meliorem formam redactis vocabulis interdum adscriptis, particulae omnes adhuc nondum collatae, pronomina omnia hic primum congesta atque enarrata, nomina propria omnia separatim commemorata. Servato textu masoretico librorumque sacrorum ordine tradito summa cura collegit et concinnatit Solomon Mandelkers. Fol. (XVI et 1532 pp.) Lipsiae. 1896. Veit et Comp. 